\title{
CARACTERIZAÇÃO FLORÍSTICA E ESTRUTURAL DE UMA FLORESTA OMBRÓFILA DENSA ALTOMONTANA DO MORRO DO ANHANGAVA, QUATRO BARRAS - PR
}

\author{
Maria Carolina G. de O. Portes ${ }^{1}$ \\ Franklin Galvão ${ }^{2}$ \\ Alexandre Koehler ${ }^{3}$
}

\begin{abstract}
RESUMO
Com o propósito de caracterizar a vegetação arbórea do alto das montanhas, realizou-se um levantamento florístico e fitossociológico de uma Floresta Ombrófila Densa Altomontana situada na face sudoeste do morro do Anhangava ( $25^{\circ} 23^{\prime} \mathrm{S}$ e $\left.49^{\circ} 00^{\prime} \mathrm{W}\right)$, município de Quatro Barras - PR, entre as altitudes de 1.250 a $1.350 \mathrm{~m}$ s.n.m.. A amostragem foi feita utilizando-se dois transectos, constituídos de 10 parcelas de $5 \times 10 \mathrm{~m}$ cada, totalizando $1.000 \mathrm{~m}^{2}$ de área amostral, onde mediu-se e identificou-se todos os indivíduos com perímetro à altura do peito igual ou superior a $10 \mathrm{~cm}$. A floresta estudada apresentou baixa diversidade de espécies, $\mathrm{H}^{\prime}=2,279$ nats/ind., alta densidade, 4.830 ind./ha, baixo porte, com altura média de 4,6 m, fustes finos e tortuosos, com diâmetro médio de $9 \mathrm{~cm}$, compondo apenas um estrato arbóreo, com $8 \mathrm{~m}$ de altura, no máximo. Encontrou-se no total 24 espécies arbóreas, onde pelo menos 3 delas são endêmicas, e 13 famílias. Com 7 espécies, Myrtaceae foi a família mais representativa, seguida por Lauraceae, no entanto, foi uma Aquifoliaceae, Ilex microdonta Reisssek, quem destacou-se, com $26 \%$ da densidade e $46 \%$ da dominância.
\end{abstract}

Palavras-chave: floresta altomontana, estrutura arbórea, florística.

\section{SPECIES COMPOSITION AND FOREST STRUCTURE AT AN UPPER MONTANE RAIN FOREST, ANHANGAVA MOUNTAIN, QUATRO BARRAS- PR}

\begin{abstract}
Species composition and forest structure were studied at an Upper Montane Rain Forest, in the Southwest face of the Anhangava mountain $\left(25^{\circ} 23^{\prime} \mathrm{S}\right.$ and $\left.49^{\circ} 00^{\prime} \mathrm{W}\right)$, at Quatro Barras, Paraná, among $1.250-1.350 \mathrm{~m}$ of altitude. Species composition and forest structure were determined through a survey of twenty plots $(5 \times 10 \mathrm{~m}$ each) where all trees $10 \mathrm{~cm}$ or higher in girth at breast height $(\mathrm{GBH})$ were measured and identified. The forest community showed high density $(4.830 \mathrm{n} / \mathrm{ha})$, low height (< $8 \mathrm{~m}$ ) and it is composed of just one story. Only 24 species of 13 families were found denoting low diversity. Three species, at least, are endemic. From these 24 species only a few dominated the community. Myrtaceae was the more representative family, however Ilex microdonta Reissek an Aquifoliaceae presented the higher density (26\%) and dominance index (46\%).
\end{abstract}

Key-words: Upper Montane Rain Forest, forest structure, species composition.

\section{INTRODUÇÃO}

As mudanças que ocorrem de natureza climática, pedológica e geomorfológica ao longo de um gradiente altitudinal são suficientes para imprimir diferenças importantes na vegetação. Nas regiões altas das serras, as condições ambientais por serem mais críticas para o desenvolvimento da vegetação, fazem com que as comunidades arbóreas ali existentes sejam estrutural, fisionomica e floristicamente bastante diversas daquelas localizadas em pisos altitudinais inferiores, configurando o que se conhece por floresta altomonontana ou floresta nebular, entre muitas outras designações (RICHARDS, 1952; EWUSIE, 1980; HALMILTON, 1995; BRUIJNZEEL \& VENEKLAAS, 1998).

\footnotetext{
${ }^{1}$ M. Sc./CNPq - mcportes@mais.sul.com.br

${ }^{2}$ Dr., Departamento de Ciências Florestais, UFPR/CNPq - fgalvao@ floresta.ufpr.br

${ }^{3}$ M. Sc., Centro de Ciências Agrárias e Ambientais, PUC-PR/CAPES - koehler@rla01.pucpr.br
} 
Localizada próxima ao cume das grandes montanhas, a partir de 1.000 - 1.200 m s.n.m. nos estados do Sul do Brasil, essa formação vegetacional está associada às altas montanhas da Serra do Mar, nos estados de Santa Catarina e Paraná, e aos Aparados da Serra, nos estados de Santa Catarina e Rio Grande do Sul, em regiões onde as chuvas orográficas são comuns devido às barreiras ocasionadas por essas serras. Ocorre em um ambiente constantemente saturado de umidade, podendo apresentar médias térmicas inferiores a $15^{\circ} \mathrm{C}$, em locais bastante declivosos, que comportam quase sempre solos rasos e com grande quantidade de matéria orgânica (IBGE, 1992; RODERJAN， 1994; FALKENBERG \& VOLTOLINI, 1994).

A vegetação responde ao aumento do grau de diversidade ambiental, com a diminuição progressiva da diversidade específica e com significativas mudanças fisionômicas e estruturais, culminando com o seu desaparecimento por completo nas grandes altitudes. No ambiente altomontano o dossel é essencialmente uniforme e homogêneo, composto por uma vegetação arbórea densa e baixa, normalmente com folhas miúdas e esclerófilas e com troncos finos, tortuosos e bastante ramificados, totalmente recobertos por musgos e epífitas (MAACK, 1981; RODERJAN \& KUNIYOSHI, 1988; LEITE \& KLEIN, 1990; IBGE, 1992). Apesar de o número de indivíduos por unidade de área aumentar de uma maneira substancial nesses ambientes, diminui o diâmetro médio e a área basal por hectare (WHITE JR., 1963; BYER \& WEAVER, 1977).

Com o objetivo de caracterizar a formação altomontana, cujas informações são insuficientes, realizou-se um estudo fitossociológico do componente arbóreo em uma Floresta Ombrófila Densa primária, localizada no morro do Anhangava, município de Quatro Barras - PR.

\section{MATERIAL E MÉTODOS}

\section{Localização e caracterização da área de estudo}

O morro do Anhangava é o ponto culminante da serra da Baitaca, localizada no município de Quatro Barras - PR, a $25^{\circ} 03^{\prime}$ de latitude Sul e $49^{\circ} 00^{\prime}$ de longitude Oeste, com 1.420 m s.n.m. (Figura 1).

O clima, segundo Koeppen, é do tipo $\mathrm{C} f b$, com verões frescos, geadas freqüentes e sem estação seca definida. Devido às cadeias montanhosas estarem localizadas próximas ao mar, agem como obstáculos aos sistemas atmosféricos tropical atlântico e polar, ocasionando chuvas orográficas e aprisionamento do ar frio, o que provocam na região elevados índices pluviométricos e de umidade relativa do ar, grande nebulosidade e temperaturas extremas (BIGARELLA, 1978; MAACK, 1981; RODERJAN \& STRUMINSKI, 1992; IAPAR, 1994; RODERJAN, 1994).

O relevo é montanhoso a escarpado, com solos pouco desenvolvidos, havendo predominância dos Solos Litólicos e Orgânicos, atualmente classificados como NEOSSOLOS LITÓLICOS Húmicos, NEOSSOLOS LITÓLICOS Hísticos e ORGANOSSOLOS FÓLICOS pelo Sistema Brasileiro de Classificação de Solos (EMBRAPA, 1999), observando-se também a ocorrência de afloramentos rochosos nas porções mais dissecadas e de CAMBISSOLOS nas porções menos íngremes (MAACK, 1981; RODERJAN, 1994).

A vegetação predominante pertence ao domínio da Floresta Ombrófila Densa, não obstante o limite leste da Floresta Ombrófila Mista faça parte do contexto vegetacional, formando áreas de contato no contraforte oeste da serra da Baitaca na faixa dos 1.000 m s.n.m. (RODERJAN \& STRUMINSKI, 1992; RODERJAN, 1994). De acordo com o IBGE (1992) e em concordância com os pisos altitudinais dominantes na região de estudo, a Floresta Ombrófila Densa é sub-dividida em duas formações: Montana (1.000 - $1.200 \mathrm{~m}$ s.n.m.) e Altomontana (1.200 - $1.420 \mathrm{~m}$ s.n.m.). A partir dos $1.250 \mathrm{~m}$ s.n.m. ocorrem, em meio a floresta altomontana, os refúgios vegetacionais, caracterizados pela vegetação rupestre, formando belas associações de plantas herbáceas e arbustivas (IBGE, 1992; RODERJAN, 1994; RODERJAN et al., 1999). 

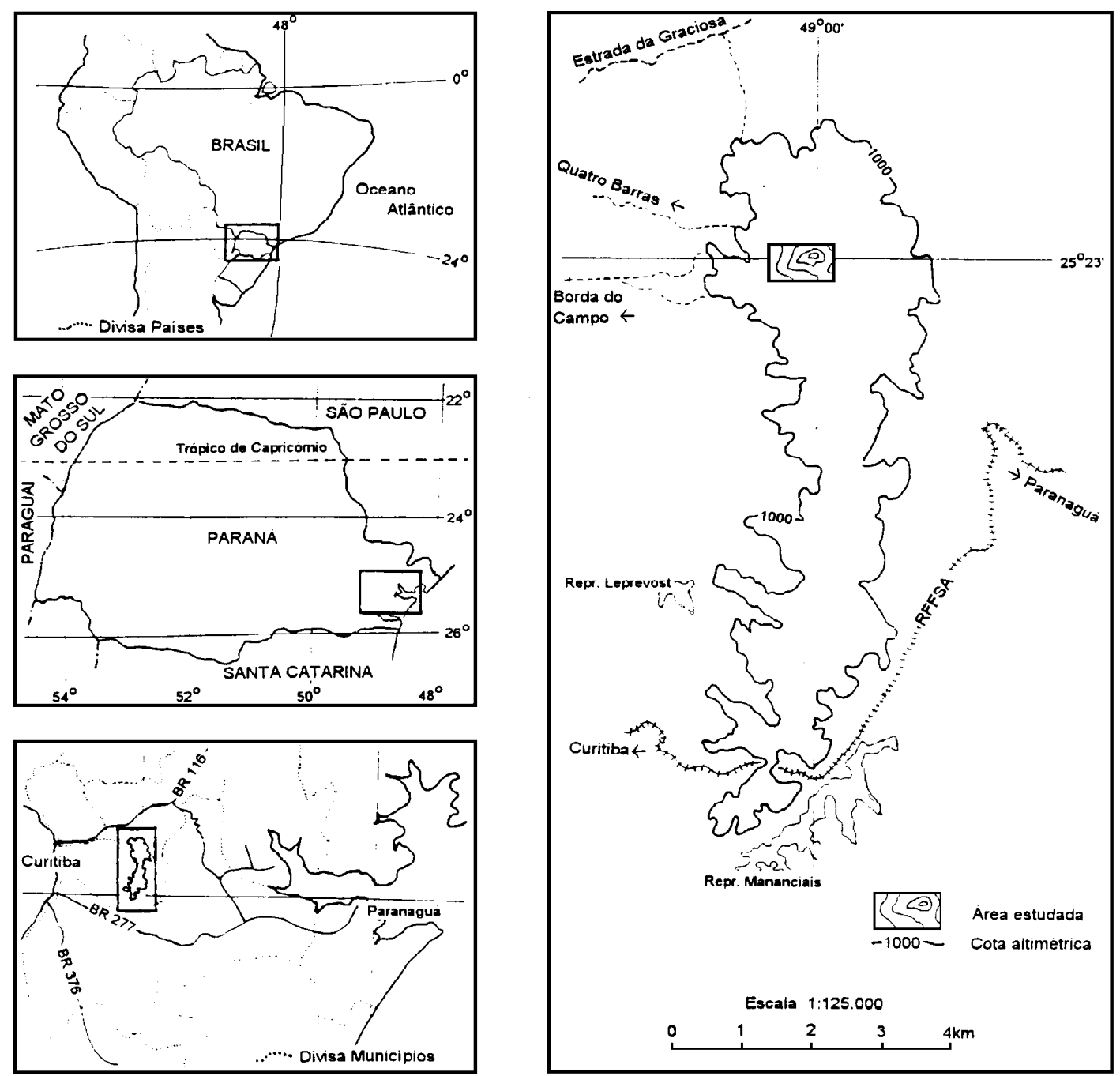

Figura 1 - Localização da área de estudo (fonte: RODERJAN, 1994)

\section{Procedimento metodológico}

A amostragem foi realizada por meio de dois transectos paralelos, dispostos no sentido do declive, constituídos, cada um, por 10 parcelas retangulares de $5 \times 10 \mathrm{~m}$, posicionadas uma após a outra, totalizando $1.000 \mathrm{~m}^{2}$ de área amostrada. Em cada parcela, todos os indivíduos com perímetro à altura do peito (PAP) igual ou superior a $10 \mathrm{~cm}$ foram medidos. Anotou-se, em uma ficha de campo, o PAP, a altura total e a altura do ponto de inversão morfológica, e avaliou-se a forma do fuste, utilizando-se três padrões de tortuosidade, e a forma da copa, segundo oito padrões pré-determinados utilizados por RODERJAN (1994), visando especialmente a elaboração de perfil esquemático.
O material botânico foi coletado, herborizado e registrado no herbário do Laboratório de Dendrologia do Departamento de Silvicultura e Manejo do Setor de Ciências Agrárias da UFPR (EFC). Para a identificação das espécies recorreu-se ao Dr. Gerdt Hatschbach, do Museu Botânico Municipal (MBM) da Prefeitura Municipal de Curitiba, ao Dr. Carlos Vellozo Roderjan, do Departamento de Ciências Florestais da UFPR, e ao pesquisador Marcos Sobral, do Curso de Farmácia da UFRGS.

Os dados obtidos em campo foram submetidos ao programa FITOPAC I (SHEPHERD, 1988), calculando-se os descritores densidade, dominância, frequiência, valor de importância, índice de diversidade de Shannon-Weaver (H') para espécies e equabilidade, segundo MUELLER-DOMBOIS 
\& ELLENBERG (1974) e MAGURRAN (1989). Também foram determinados os valores máximos, médios e mínimos do diâmetro e da altura para cada espécie e família. Com base nesses dados, obteve-se as informações quali-quantitativas que possibilitaram a interpretação e avaliação da vegetação estudada.

\section{RESULTADOS E DISCUSSÃO}

Nos $1.000 \mathrm{~m}^{2}$ amostrados foram encontrados 483 indivíduos arbóreos, 449 vivos e 34 mortos, pertencentes a apenas 24 espécies e a 13 famílias (Tabela 1), o que resultou em uma diversidade ( $\left.H^{\prime}\right)$ de 2,279 nats/ind. e uma equabilidade de 0,708 , valores bastante baixos, no entanto esperados.

Tabela 1 - Composição florística arbórea da Floresta Ombrófila Densa Altomontana e número de indivíduos por espécie

\begin{tabular}{lll}
\hline FAMÍLIA & ESPÉCIE & $\mathbf{n}^{\mathbf{0}}$ de ind. \\
\hline AQUIFOLIACEAE & Ilex chamaedrifolia Reissek & 34 \\
& Ilex microdonta Reissek & 130 \\
ASTERACEAE & Vernonia quinqueflora Lessing & 1 \\
BIGNONIACEAE & Tabebuia catarinensis A. Gentry & 9 \\
CLETHRACEAE & Clethra uleana Sleumer & 1 \\
CUNONIACEAE & Lamanonia speciosa (Camb.) L. B. Smith & 1 \\
& Weinmannia humilis Engler & 1 \\
FLACOURTIACEAE & Xylosma pseudosalzmannii Sleumer & 1 \\
LAURACEAE & Ocotea catharinensis Mez & 15 \\
& Ocotea corymbosa (Meisner) Mez & 2 \\
& Ocotea daphnifolia (Meisner) Mez & 5 \\
MYRSINACEAE & Persea major (Ness.) Kopp. & 1 \\
MYRTACEAE & Rapanea parvifolia (A. D. C.) Mez & 9 \\
& Blepharocalyx salicifolius (Kunth) Berg & 74 \\
& Eugenia neomyrtifolia M. Sobral & 10 \\
& Gomidesia sellowiana Berg & 9 \\
PODOCARPACEAE & Myrcia obtecta (Berg) Kiearskov & 11 \\
RHAMNACEAE & Myrcia richardiana Berg & 11 \\
THEACEAE & Pimenta pseudocaryophyllus (Gomez) Landrum & 1 \\
WINTERACEAE & Siphoneugena reitzii Legrand & 100 \\
\hline
\end{tabular}

A diversidade observada é resultante do aumento do grau de adversidade ocasionada com a elevação da altitude. Sob condições pedo-climáticas críticas somente algumas espécies conseguem se estabelecer nestes locais. Este fato é comprovado por outros autores em diferentes florestas altomontanas, como WHITE JR. (1963), que estudou a variação na composição florística e na estrutura das florestas com a altitude nas montanhas Luquillo, Porto Rico, encontrando 15 espécies a $598 \mathrm{~m}$ de altitude e apenas 6 a $1.021 \mathrm{~m}$. Em amostragens de florestas altomontanas no Paraná, RODERJAN (1994) encontrou 25 espécies e ROCHA (1999) 29 espécies.

Segundo VELOSO \& GÓES-FILHO (1982), a florística nesses ambientes é representada por espécies endêmicas, embora suas famílias sejam de dispersão universal. Para o presente caso, constatou-se que apenas três das 24 espécies encontradas poderiam ser consideradas endêmicas - Clethra uleana, Tabebuia catarinensis e Weinmannia humilis não sendo observadas em outros pisos altitudinais ou em outras unidades vegetacionais. No entanto, é possível que em um estudo mais amplo, incluindo outros pontos de amostragem, haja um sensível aumento no número de espécies, inclusive daquelas que poderiam ser enquadradas como endêmicas.

Além do endemismo e da baixa diversidade, outra característica comum às florestas altomontanas é a alta densidade apresentada, que no presente caso foi equivalente a 4.830 ind./ha (Tabela 2). RODERJAN (1994) encontrou 4.418 ind./ha para uma comunidade localizada próxima a 
esta área de estudo e ROCHA (1999) 4.012 ind./ha para floresta altomontana em Morretes, Paraná, a $1.385 \mathrm{~m}$ de altitude, ambos utilizando um PAP mínimo igual ou superior a $10 \mathrm{~cm}$. WEAVER et al. (1986) encontraram 2.650, 4.050 e 4.312 ind./ha, com DAP igual ou superior a $10 \mathrm{~cm}($ PAP $>31 \mathrm{~cm})$ para três florestas altomontanas localizadas nas montanhas Luquillo, Porto Rico. Vários outros autores, como RICHARDS (1952), EWUSIE (1980), MAACK (1981), LEITE \& KLEIN (1990) e HAMILTON et al. (1994), quando caracterizaram as florestas nebulares, destacaram a alta densidade e a baixa diversidade apresentadas.

Tabela 2 - Número de indivíduos, de espécies e porcentagem de espécies por família na Floresta Ombrófila Densa Altomontana

\begin{tabular}{lllll}
\hline \multicolumn{1}{c}{ FAMÍLIA } & $\mathbf{n}^{\mathbf{0}}$ de spp. & \% de spp. & $\mathbf{n}^{\mathbf{0}}$ de ind. & $\mathbf{n}^{\mathbf{0}}$ de ind./ha \\
\hline Myrtaceae & & & & 2.160 \\
Aquifoliaceae & 7 & 29,17 & 216 & 1.640 \\
Lauraceae & 2 & 8,33 & 164 & 230 \\
Winteraceae & 4 & 16,67 & 23 & 110 \\
Podocarpaceae & 1 & 4,17 & 11 & 90 \\
Bignoniaceae & 1 & 4,17 & 9 & 90 \\
Myrsinaceae & 1 & 4,17 & 9 & 20 \\
Cunoniaceae & 1 & 4,17 & 9 & 20 \\
Rhamnaceae & 2 & 8,33 & 2 & 10 \\
Theaceae & 1 & 4,17 & 2 & 10 \\
Clethraceae & 1 & 4,17 & 1 & 10 \\
Flacourtiaceae & 1 & 4,17 & 1 & 10 \\
Asteraceae & 1 & 4,17 & 1 & 340 \\
\hline Mortas & 1 & 4,17 & 1 & 4.830 \\
\hline Total & - & - & 483 & \\
\hline
\end{tabular}

Poucas famílias dominam este ambiente, sendo Myrtaceae a família mais importante dessa associação, com 7 espécies e 6 gêneros (Blepharocalyx salicifolius, Siphoeugena reitzii, Myrcia obtecta, M. richardiana, Eugenia neomyrtifolia, Gomidesia sellowiana e Pimenta pseudocaryophyllus), seguida de Lauraceae, com 4 espécies e 2 gêneros. As famílias Aquifoliaceae e Cunoniaceae são representadas por duas espécies e as demais por uma espécie cada (Figura 2).

Outros autores, estudando a composição florística de florestas altomontanas, citaram essas mesmas famílias como representativas, mencionando também a ocorrência de Podocarpaceae, Winteraceae, Bignoniaceae, Clethraceae e Theaceae, entre outras (HUECK, 1972; MAACK, 1981;
VELOSO \& GÓES-FILHO, 1982; RODERJAN \& KUNIYOSHI, 1988; LEITE \& KLEIN, 1990; RODERJAN, 1994; ROCHA, 1999). Espécies das famílias Bignoniaceae e Lauraceae também são dominantes nas florestas altomontanas da região do Equador (WHITE JR., 1963).

Observando a Tabela 3 percebe-se que, apesar de Myrtaceae ser a família mais representativa dessa associação, é Ilex microdonta, uma Aquifoliaceae, a espécie mais importante desta comunidade, apresentando os maiores índices relativos de densidade $(26,92 \%)$ e de dominância $(46,15 \%)$, resultando em um valor de importância (VI) de 84,38. O segundo e o terceiro maiores VI são 42,24 e 39,38, pertencentes, respectivamente, a duas espécies de Myrtaceae, Blepharocalyx salicifolius e Siphoneugena reitzi. 


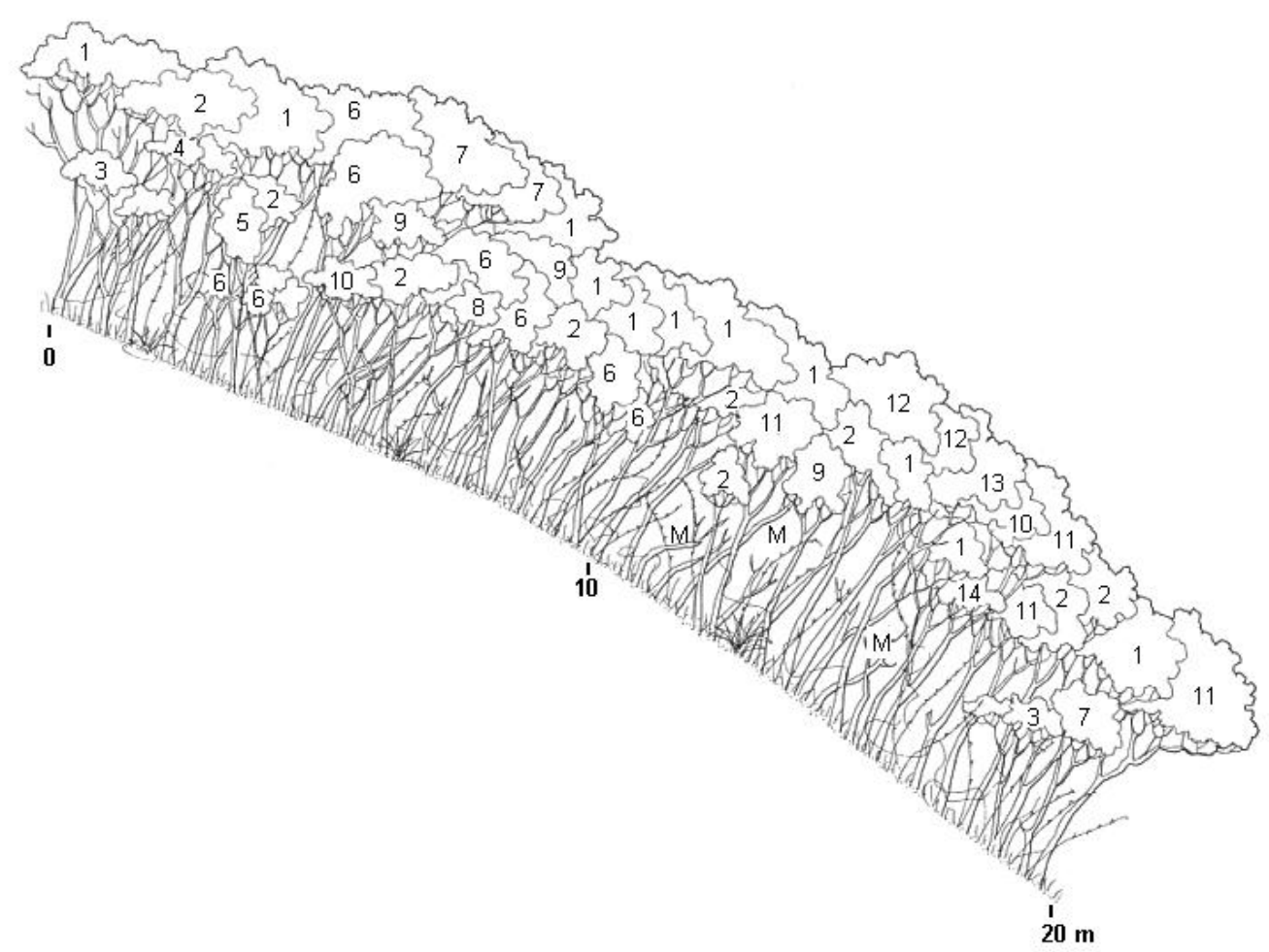

Figura 2 - Perfil esquemático da floresta altomontana, onde: 1 - Ilex microdonta; 2 - Blepharocalyx salicifolius; 3 - Eugenia myrtifolia; 4 -Tabebuia catarinensis; 5 -Rapanea parvifolia; 6 -Siphoneugena reitzii; 7 -Ilex chamaedrifolia; 8 - Lamanonia speciosa; 9 -Drimys brasiliensis; 10 -Podocarpus sellowii; 11 -Ocotea catharinensis; 12 - Laplacea fruticosa; 13 - Ocotea corymbosa; 14 - Myrcia richardiana; M - mortas

Tabela 3 - Densidade, dominância, freqüência e valor de importância (VI) das espécies arbóreas encontradas na Floresta Ombrófila Densa Altomontana

\begin{tabular}{|c|c|c|c|c|c|c|c|}
\hline \multirow[b]{2}{*}{ Espécie } & \multicolumn{2}{|c|}{ Densidade } & \multicolumn{2}{|c|}{ Dominância } & \multicolumn{2}{|c|}{ Freqüência } & \multirow[b]{2}{*}{ VI } \\
\hline & $\begin{array}{l}\text { abs. } \\
\text { no/ha }\end{array}$ & $\begin{array}{l}\text { rel. } \\
\%\end{array}$ & $\begin{array}{l}\text { abs. } \\
\mathbf{m}^{2} / \mathrm{ha}\end{array}$ & $\begin{array}{l}\text { rel. } \\
\%\end{array}$ & $\begin{array}{l}\text { abs. } \\
\%\end{array}$ & $\begin{array}{l}\text { rel. } \\
\%\end{array}$ & \\
\hline Ilex microdonta & $1.300,00$ & 26,92 & 19,32 & 46,15 & 90,00 & 11,32 & 84,38 \\
\hline Blepharocalyx salicifolius & 740,00 & 15,32 & 6,01 & 14,34 & 100,00 & 12,58 & 42,24 \\
\hline Siphoneugena reitzii & $1.000,00$ & 20,70 & 3,34 & 7,99 & 85,00 & 10,69 & 39,38 \\
\hline Ilex chamaedrifolia & 340,00 & 7,04 & 1,85 & 4,42 & 75,00 & 9,43 & 20,90 \\
\hline Ocotea catharinensis & 150,00 & 3,11 & 2,94 & 7,02 & 40,00 & 5,03 & 15,16 \\
\hline Podocarpus sellowii & 90,00 & 1,86 & 0,88 & 2,11 & 45,00 & 5,66 & 9,63 \\
\hline Myrcia obtecta & 110,00 & 2,28 & 1,62 & 3,87 & 25,00 & 3,14 & 9,29 \\
\hline Drimys brasiliensis & 110,00 & 2,28 & 0,40 & 0,95 & 45,00 & 5,66 & 8,89 \\
\hline Myrcia richardiana & 110,00 & 2,28 & 1,01 & 2,41 & 25,00 & 3,14 & 7,83 \\
\hline Eugenia neomyrtifolia & 100,00 & 2,07 & 0,15 & 0,36 & 35,00 & 4,40 & 6,84 \\
\hline Tabebuia catarinensis & 90,00 & 1,86 & 0,12 & 0,28 & 35,00 & 4,40 & 6,54 \\
\hline Gomidesia sellowiana & 90,00 & 1,86 & 0,17 & 0,42 & 25,00 & 3,14 & 5,42 \\
\hline Rapanea parvifolia & 90,00 & 1,86 & 0,18 & 0,42 & 15,00 & 1,89 & 4,17 \\
\hline Ocotea daphnifolia & 50,00 & 1,04 & 0,39 & 0,94 & 15,00 & 1,89 & 3,86 \\
\hline Ocotea corymbosa & 20,00 & 0,41 & 0,61 & 1,45 & 10,00 & 1,26 & 3,12 \\
\hline Laplacea fruticosa & 10,00 & 0,21 & 0,62 & 1,47 & 5,00 & 0,63 & 2,31 \\
\hline Rhamnus sphaerosperma & 20,00 & 0,41 & 0,02 & 0,04 & 10,00 & 1,26 & 1,71 \\
\hline Weinmannia humilis & 10,00 & 0,21 & 0,16 & 0,37 & 5,00 & 0,63 & 1,21 \\
\hline Clethra uleana & 10,00 & 0,21 & 0,14 & 0,34 & 5,00 & 0,63 & 1,17 \\
\hline Xylosma pseudosalzmannii & 10,00 & 0,21 & 0,09 & 0,21 & 5,00 & 0,63 & 1,05 \\
\hline Pimenta pseudocaryophyllus & 10,00 & 0,21 & 0,03 & 0,07 & 5,00 & 0,63 & 0,91 \\
\hline Vernonia quinqueflora & 10,00 & 0,21 & 0,01 & 0,03 & 5,00 & 0,63 & 0,87 \\
\hline Persea major & 10,00 & 0,21 & 0,01 & 0,02 & 5,00 & 0,63 & 0,86 \\
\hline Lamanonia speciosa & 10,00 & 0,21 & 0,008 & 0,02 & 5,00 & 0,63 & 0,86 \\
\hline Mortas & 340,00 & 7,04 & 1,80 & 4,29 & 80,00 & 10,06 & 21,39 \\
\hline Total & $4.830,00$ & 100,0 & 41,87 & 100,0 & 795,00 & 100,0 & 300,00 \\
\hline
\end{tabular}


B. salicifolius junto com I. microdonta representam quase metade dos indivíduos dessa comunidade, $42 \%$. Esta característica de uma ou de poucas espécies dominarem o ambiente também foi observada por RODERJAN (1994), que obteve I. microdonta como espécie mais importante, com $36,2 \%$ de densidade e $57,8 \%$ de dominância, seguida de S. reitzii, com $19,8 \%$ de densidade e $11,0 \%$ de dominância, e de $B$. salicifolius, com $6,4 \%$ de densidade e 5,9\% de dominância. ROCHA (1999), apesar de ter encontrado uma Lauraceae - Ocotea catharinensis - como espécie mais importante no seu levantamento, também apontou Myrtaceae como família mais representativa.

A área basal encontrada, $41,87 \mathrm{~m}^{2} / \mathrm{ha}$, é bastante superior aos valores apresentados por RODERJAN (1994), 29,29 $\mathrm{m}^{2} / \mathrm{ha}$, e por ROCHA (1999), 35,24 m²/ha, contudo está dentro da média das áreas basais das florestas altomontanas estudadas por WEAVER et al. (1986), que variaram de 38 a $65 \mathrm{~m}^{2} / \mathrm{ha}$.

Apesar de I. microdonta apresentar os maiores valores de densidade e de dominância, sua ocorrência não se deu em todas as parcelas, tendo uma frequiência de $90 \%$. S. reitzii, com a segunda maior densidade, apresenta freqüência de $85 \%$, enquanto que $B$. salicifolius ocorre em todas as unidades amostrais.

Ainda que a área basal total seja alta, a floresta estudada é composta dominantemente de muitos indivíduos finos, com PAP raramente ultrapassando $45 \mathrm{~cm}$ (Tabela 4).

Tabela 4 - Altura e perímetro das espécies arbóreas encontradas na Floresta Ombrófila Densa Altomontana

\begin{tabular}{|c|c|c|c|c|c|c|}
\hline \multirow[t]{2}{*}{ Espécie } & \multicolumn{3}{|c|}{ Altura (m) } & \multicolumn{3}{|c|}{ Perímetro $(\mathrm{cm})$} \\
\hline & mínima & média & máxima & mínimo & médio & máximo \\
\hline Ilex microdonta & 2,5 & 5,2 & 7,5 & 10 & 39 & 104 \\
\hline Blepharocalyx salicifolius & 2,0 & 5,1 & 7,5 & 10 & 29 & 64 \\
\hline Siphoneugena reitzii & 2,5 & 4,6 & 6,5 & 10 & 19 & 61 \\
\hline Ilex chamaedrifolia & 2,0 & 4,7 & 6,5 & 10 & 23 & 53 \\
\hline Ocotea catharinensis & 3,5 & 5,7 & 7,5 & 12 & 43 & 80 \\
\hline Podocarpus sellowii & 3,0 & 5,4 & 7,5 & 17 & 33 & 51 \\
\hline Myrcia obtecta & 2,5 & 5,5 & 8,0 & 11 & 35 & 100 \\
\hline Drimys brasiliensis & 2,5 & 4,2 & 5,0 & 10 & 20 & 38 \\
\hline Myrcia richardiana & 4,0 & 5,3 & 7,0 & 14 & 31 & 50 \\
\hline Eugenia neomyrtifolia & 2,0 & 3,3 & 5,0 & 11 & 14 & 20 \\
\hline Tabebuia catarinensis & 2,5 & 4,4 & 6,0 & 10 & 13 & 17 \\
\hline Gomidesia sellowiana & 3,0 & 3,8 & 5,5 & 10 & 15 & 20 \\
\hline Rapanea parvifolia & 3,0 & 3,8 & 4,5 & 10 & 15 & 23 \\
\hline Ocotea daphnifolia & 3,5 & 5,2 & 7,5 & 10 & 26 & 57 \\
\hline Ocotea corymbosa & 7,0 & 7,5 & 8,0 & 53 & 61 & 69 \\
\hline Laplacea fruticosa & 7,0 & 7,0 & 7,0 & 88 & 88 & 88 \\
\hline Rhamnus sphaerosperma & 4,0 & 4,0 & 4,0 & 10 & 10 & 11 \\
\hline Weinmannia humilis & 5,5 & 5,5 & 5,5 & 44 & 44 & 44 \\
\hline Clethra uleana & 4,0 & 4,0 & 4,0 & 42 & 42 & 42 \\
\hline Xylosma pseudosalzmannii & 6,0 & 6,0 & 6,0 & 34 & 34 & 34 \\
\hline Pimenta pseudocaryophyllus & 5,0 & 5,0 & 5,0 & 19 & 19 & 19 \\
\hline Vernonia quinqueflora & 4,0 & 4,0 & 4,0 & 13 & 13 & 13 \\
\hline Persea major & 2,5 & 2,5 & 2,5 & 11 & 11 & 11 \\
\hline Lamanonia speciosa & 3,0 & 3,0 & 3,0 & 10 & 10 & 10 \\
\hline Mortas & - & - & - & 10 & 24 & 46 \\
\hline
\end{tabular}

Verificou-se que apesar de o perímetro alcançar até $104,0 \mathrm{~cm}$, a grande maioria dos indivíduos ocorre em classes perimétricas que variam de 10,0 a 45,0 cm (Figura 3). Com relação a altura, os indivíduos atingem até 8,0 $\mathrm{m}$, contudo os valores médios estão entre $4 \mathrm{e}$
$6 \mathrm{~m}$ (altura média de 4,6 m), valores esses compatíveis com os mencionados por outros autores (HUECK, 1972; RODERJAN \& KUNIYOSHI, 1988; LEITE \& KLEIN, 1990) (Figura 4). RODERJAN (1994) e ROCHA 
(1999) encontraram uma altura média um pouco inferior, 3,5 e $3 \mathrm{~m}$, respectivamente.

ARENDS et al. (1991/1992), estudando uma floresta altomontana em Mérida, Venezuela, também encontraram a maioria dos indivíduos pertencente às classes diamétricas de 3 a 5 e de 5 a 7 (PAP equivalente a 10 a 15 e de 15 a $22 \mathrm{~cm}$ ), com altura média entre 4 e $6 \mathrm{~m}$, raramente ultrapassando $8,0 \mathrm{~m}$. WHITE JR. (1963) verificou, nas montanhas Luquillo, Porto Rico, que a altura das árvores dominantes diminuiu de $18 \mathrm{~m}$ a $598 \mathrm{~m}$ de altitude para $4 \mathrm{~m}$ a 1.021 m e o PAP médio de $63 \mathrm{~cm}$ passou a ser de 25 $\mathrm{cm}$, enquanto que o perímetro máximo caiu de $480 \mathrm{~cm}$ para $64 \mathrm{~cm}$.

Como o conjunto de indivíduos não diferenciam-se entre si de maneira importante em relação a altura, agregando-se em poucas classes de distribuição (Figura 4), forma-se um único e denso estrato arbóreo, composto por árvores finas de baixa estatura.
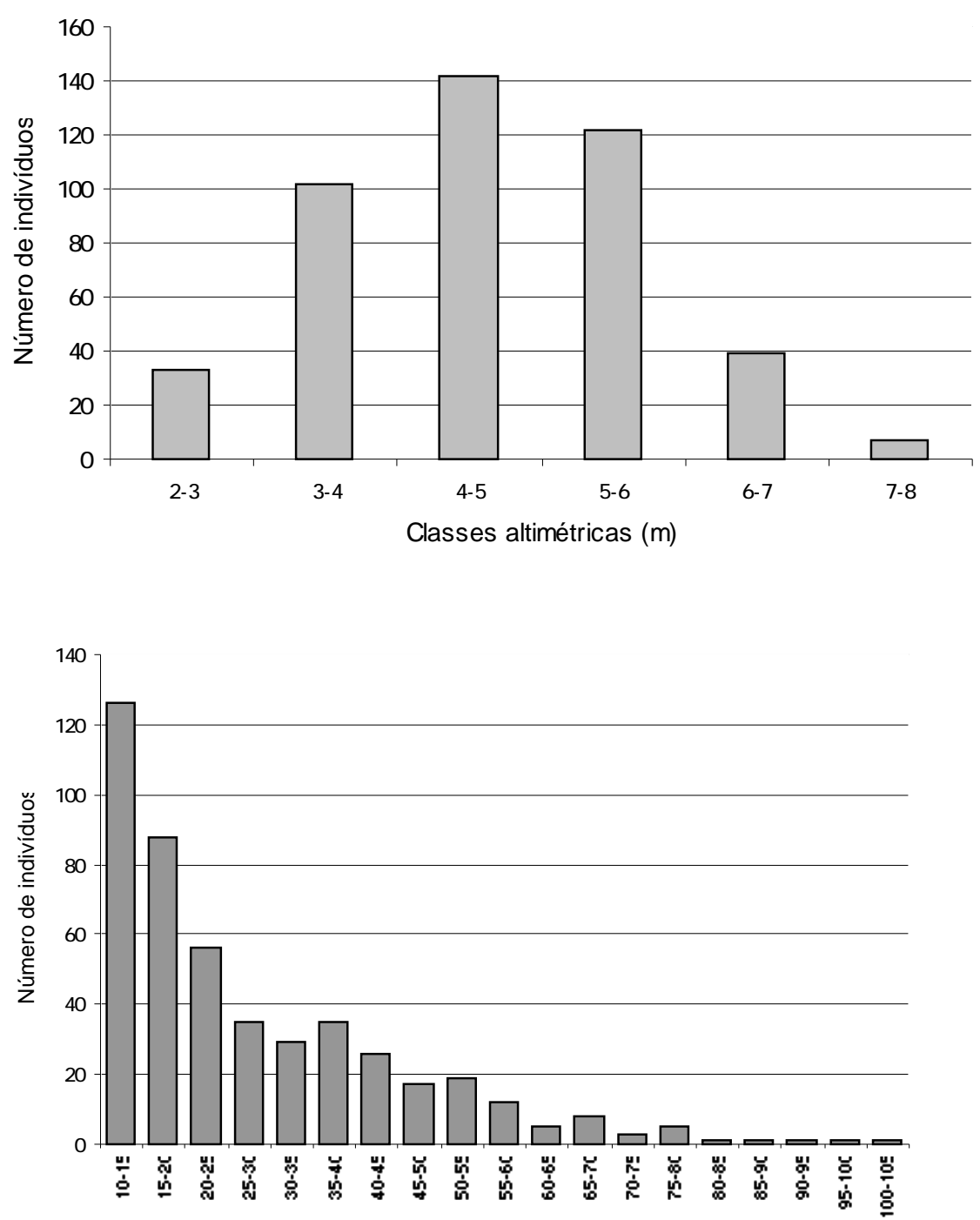

Classes perimétricas $(\mathrm{cm})$

Figura 3 - Distribuição das classes perimétricas dos indivíduos amostrados

Figura 4 - Distribuição das classes altimétricas dos indivíduos amostrados 


\section{CONCLUSÕES}

Foram encontradas 24 espécies arbóreas, sendo Ilex microdonta (Aquifoliaceae), Blepharocalyx salicifolius (Myrtaceae) e Siphoneugena reitzii (Myrtaceae) as que mais se destacaram em relação aos parâmetros fitossociológicos empregados. As famílias com maior número de espécies foram Myrtaceae, Lauraceae, Aquifoliaceae e Cunoniaceae.

Das espécies observadas, constituem como possíveis endêmicas somente Clethra uleana, Tabebuia catarinensis e Weinmannia humilis, sendo as demais comuns a outras formações ou unidades vegetacionais.

Pôde-se constatar que a formação arbórea altomontana apresenta como características a existência de alta densidade de indivíduos de fuste finos e tortuosos, compondo apenas um estrato denso, resultante da dominância de uma ou de poucas espécies.

\section{BIBLIOGRAFIA CITADA}

ARENDS, E.; VILLAQUIRÁN, A.; CALDERÓN, O. Caracterizacion de la vegetacion secundaria en un area talada de la Selva Nublada. Rev. For. Venez., Merida, v. 25-26, n. 35-36, p. 15-22, 1991-1992.

BIGARElla, J. J. A Serra do Mar e a porção oriental do estado do Paraná. Curitiba: Governo do Estado do Paraná - ADEA, 1978.

BRUIJNZEEL, L. A.; VENEKLAAS, E. J..Climatic conditions and Tropical Montane Forest productivity: the fog has not lifted yet. Ecology, v. 79, n. 1, p. 3-9, 1998.

BYER, M. D.; WEAVER, P. L. Early secondary succession in an Elfin Woodland in the Luquillo Mountains of Puerto Rico. Biotropica, v. 9, n. 1, p. 35-47, 1977.

EMBRAPA. Sistema brasileiro de classificação de solos: $5^{\text {a }}$ aproximação. Brasília: Serviço de Produção de Informação - SPI, 1999.
EWUSIE, J. Y. Elements of tropical ecology. London: Heinemann Educational Books Ltd., 1980.

FALKENBERG, D. B.; VOLTOLINI, J. C. The Montane Cloud Forest in southern Brazil. In: Tropical Montane Cloud Forests. Ecological Studies, vol. 110, New York: Springer-Velag, p.138149, 1994.

HAMILTON, L. S.; JUVIK, J. O.; SCATENA, F. N. The Puerto Rico Tropical Cloud Forest Symposium: Introduction and workshop synthesis. In: Tropical Montane Cloud Forests. Ecological Studies, vol. 110. New York: Springer-Velag, p.1-23, 1994.

HAMILTON, L. S. Mountain cloud forest conservation and research: a synopsis. Mountain Research and Development, v. 15, n. 3, p. 259-266, 1995.

HUECK, K. As florestas da América do Sul. Brasília: Editora Universidade de Brasília, 1972.

IAPAR. Cartas climáticas do estado do Paraná. Londrina:IAPAR, 1994. (Documento, 18)

IBGE. Manual técnico da vegetação brasileira. Série Manuais Técnicos em Geociências, Rio de Janeiro, n. 1, 92 p, 1992.

LEITE, P. F.; KLEIN, R. M. Vegetação. In: Geografia do Brasil, região Sul. v. 2. Rio de Janeiro: IBGE, 1990. p.113150.

MAACK, R. Geografia física do estado do Paraná. 2. ed. Rio de Janeiro: Livraria José Olympio Editora, 1981.

MAGURRAN, A.E. Diversidad ecológica y su medición. Barcelona: Vedrá, 1989.

MUELLER-DOMBOIS D.; ELLENBERG, H. Aims and methods of vegetation ecology. New York: John Wiley \& Sons, 1974.

RICHARDS, P. W. The Tropical Rain Forest. London: Cambridge University Press, 1952. 
ROCHA, M. do R. L. Caracterização fitossociológica e pedológica de uma Floresta Ombrófila Densa Altomontana no Parque Estadual Pico do Marumbi Morretes, PR. Curitiba, 1999. 81 f. Dissertação (Mestrado em Engenharia Florestal). Setor de Ciências Agrárias, Universidade Federal do Paraná.

RODERJAN, C. V.; KUNIYOSHI, Y. S. Macrozoneamento florístico da Área de Proteção Ambiental - APA Guaraqueçaba. Curitiba: FUPEF, 1988. 54 p. Relatório Técnico.

RODERJAN, C. V.; STRUMINSKI, E. Serra da Baitaca - caracterização e proposta de manejo. Curitiba: FUPEF/FBPN, 1992. 102 p. Relatório Técnico.

RODERJAN, C. V. A Floresta Ombrófila Densa Altomontana do morro do Anhangava, Quatro Barras, PR Aspectos climáticos, pedológicos e fitossociológicos. Curitiba, 1994. $119 \mathrm{f}$. Tese (Doutorado em Engenharia Florestal). Setor de Ciências Agrárias, Universidade Federal do Paraná.

RODERJAN, C. V.; PORTES, M. C .G. de O.; KOEHLER, A.; LACERDA, M. R.; AMADO, E. F. Estudos fitossociológicos realizados em Florestas Nebulares (Floresta Ombrófila Densa Altomontana) na Serra do Mar paranaense. In: Congresso Nacional de Botânica, 50, 1999, Blumenau, 1999, Anais... Blumenau, 1999. p. 235.

SHEPHERD, G. J. Fitopac I - versão preliminar. Campinas: UNICAMP, 1988.

VELOSO, H. P.; GÓES-FILHO, L. Fitogeografia brasileira, classificação fisionômico-ecológica da vegetação neotropical. Boletim técnico, série vegetação n. 1. RADAMBRASIL, Salvador: Ministério das Minas e Energia, 1982. 85 p.

WEAVER, P. L.; MEDINA, E.; POOL, D.; DUGGER, K.; GONZALESLIBOY, J.; CUEVAS, E. Ecological observations in the Dwarf Cloud Forest of the Luquillo Mountains in Puerto Rico. Biotropica, v. 18, n.1, p. 79-85, 1986.

WHITE JR., H. H. Variation of stand structure correlated with altitude, in the Luquillo Mountains. Caribbean Forester, v. 24, n.1, p. 46-52, 1963. 